\title{
Drosophila Neuroligin 4 Regulates Sleep through Modulating GABA Transmission
}

\author{
Yi Li, ${ }^{1 \star}$ Zikai Zhou, ${ }^{1 \star}$ Xinwang Zhang, ${ }^{1}$ Huawei Tong, ${ }^{1}$ Peipei Li, ${ }^{1}$ Zi Chao Zhang, ${ }^{1}$ Zhengping Jia, ${ }^{2}$ Wei Xie, ${ }^{1}$ \\ and Junhai $\operatorname{Han}^{1}$ \\ ${ }^{1}$ Institute of Life Sciences, the Key Laboratory of Developmental Genes and Human Disease, Southeast University, Nanjing 210096, China and \\ ${ }^{2}$ Neurosciences and Mental Health Program, The Hospital for Sick Children, University of Toronto, Toronto, Ontario, Canada M5S 1A1
}

\begin{abstract}
Sleep is an essential and evolutionarily conserved behavior that is closely related to synaptic function. However, whether neuroligins (Nlgs), which are cell adhesion molecules involved in synapse formation and synaptic transmission, are involved in sleep is not clear. Here, we show that Drosophila Nlg4 (DNlg4) is highly expressed in large ventral lateral clock neurons (l-LNvs) and that l-LNv-derived DNlg4 is essential for sleep regulation. GABA transmission is impaired in mutant l-LNv, and sleep defects in $d n l g 4$ mutant flies can be rescued by genetic manipulation of GABA transmission. Furthermore, $d n l g 4$ mutant flies exhibit a severe reduction in $\mathrm{GABA}_{\mathrm{A}}$ receptor RDL clustering, and DNlg4 associates with RDLs in vivo. These results demonstrate that DNlg4 regulates sleep through modulating GABA transmission in l-LNvs, which provides the first known link between a synaptic adhesion molecule and sleep in Drosophila.
\end{abstract}

\section{Introduction}

Sleep is an essential and evolutionarily conserved behavior exhibited by animals ranging from worm to human (Cirelli, 2009; Crocker and Sehgal, 2010), yet it remains one of the least understood biological phenomena. Drosophila, an advantageous animal for genetic investigation, also exhibits sleep-like behavior (Nitz et al., 2002; van Swinderen et al., 2004). Thus, this species has been used to dissect the molecular underpinnings of sleep, leading to the identification of genes, circuits, and biological processes that are involved in sleep (Shaw et al., 2000; Cirelli et al., 2005; Joiner et al., 2006; Pitman et al., 2006). As in mammals, sleep in Drosophila is governed by both circadian and homeostatic regulation (Hendricks et al., 2000; Shaw et al., 2000). In particular, large ventral lateral neurons (l-LNvs) mediate lightdriven arousal through the release of pigment dispersing factor (PDF; Parisky et al., 2008; Shang et al., 2008; Sheeba et al., 2008b). The electrical activity of l-LNvs is circadian regulated and suppressed at night by inhibitory neurotransmitters such as GABA (Shang et al., 2008; Sheeba et al., 2008b; Sehgal and Mignot, 2011). Therefore, the inhibition of l-LNvs by GABAergic inputs

\footnotetext{
Received Feb. 21, 2013; revised Aug. 14, 2013; accepted Aug. 14, 2013.

Author contributions: J.H. designed research; Y.L., Z.Z., and P.L. performed research; X.Z. and W.X. contributed unpublished reagents/analytic tools; Y.L., Z.Z., H.T., and Z.J. analyzed data; Z.C.Z., W.X., and J.H. wrote the paper.

This work was supported by the National Natural Science Foundation of China (91132706) to J.H., the National Basic Research Program (973 Program) Grant (2012CB517903) and the National Natural Science Foundation of China (31171041 and 30930051) to W.X., and the Scientific Research Foundation of Graduate School of Southeast University (YBJJ1123) to Y.L. We thank Dr. Julie H. Simpson for providing rdl-Gal4 flies, Dr. Li Liu for providing 104y-Gal4 flies, the Bloomington stock center and Vienna Drosophila RNAi stock center for providing flies, and members of the Han laboratory for critical comments on this manuscript.

${ }^{*}$ Y.L. and Z.Z. contributed equally to this work.

The authors declare no competing financial interests.

Correspondence should be addressed to either of the following: Junhai Han or Wei Xie, Institute of Life Sciences, Southeast University, 2 Sipailou Road, Nanjing 210096, China, E-mail: junhaihan@seu.edu.cn; or wei.xie@seu.edu.cn.

DOI:10.1523/JNEUROSCI.0819-13.2013

Copyright $\odot 2013$ the authors $\quad 0270-6474 / 13 / 3315545-10 \$ 15.00 / 0$
}

serves to promote sleep (Agosto et al., 2008; Parisky et al., 2008; Chung et al., 2009).

Neuroligins (Nlgs) are synaptic adhesion molecules involved in synapse formation and synaptic transmission (Scheiffele et al., 2000; Varoqueaux et al., 2006). Four Nlg homologs (Nlg1-Nlg4) have been identified in mammals (Ichtchenko et al., 1996), with different homologs located in different classes of synapses (Song et al., 1999; Budreck and Scheiffele, 2007; Hoon et al., 2011). All Nlgs are expressed in the hypothalamus (Varoqueaux et al., 2004, 2006; Mungenast and Ojeda, 2005), which is a brain region that is essential for sleep regulation. A recent study showed that $n \lg 1$ knock-out mice are not able to sustain wakefulness and spend more time in nonrapid eye movement sleep than wild-type mice (El Helou et al., 2013). However, the potential roles of other Nlg homologs in sleep, especially those that regulate inhibitory synapses, are largely unknown.

Four Drosophila Nlgs (DNlgs) have been identified or are predicted to exist: DNlg1 (CG31146), DNlg2 (CG13772), DNlg3 (CG34127), and DNlg4 (CG34139; Banovic et al., 2010). Phylogenetic analysis of Nlg sequences from multiple species suggests that Nlg homologs diversified independently during evolution in both vertebrates and insects (Banovic et al., 2010; Knight et al., 2011). As individual DNlgs are difficult to match with specific human orthologs (Banovic et al., 2010), their nomenclature is based on their similarity to honeybee Nlgs (Banovic et al., 2010). So far, only DNlg1 and DNlg2 have been functionally characterized (Banovic et al., 2010; Sun et al., 2011; Chen et al., 2012). In the present study, we show that DNlg4 promotes sleep through mediating $\mathrm{GABA}_{\mathrm{A}}$ receptor $\mathrm{RDL}$ clustering and modulating GABA transmission in l-LNvs, thereby providing a direct link between a synaptic adhesion molecule and sleep in Drosophila.

\section{Materials and Methods}

Animals. Flies were raised at $25^{\circ} \mathrm{C}$ (except those used in the experiments shown in Fig. 5) with a $12 \mathrm{~h}$ light/dark (LD) cycle. $p B a c\{R B\} c^{2} c^{e 01254}$ and 
$p B a c\{W H\} f 01735$ flies were purchased from the Exelixis collection at Harvard Medical School. pBac \{SAstopDsRed $\}^{L L 01874}$ flies were obtained from the Drosophila Genomics Research Center. UAS-nlg4-RNAi flies correspond to Vienna Drosophila RNAi Center stocks 6792 . Wild-type flies were $w^{1118}$. Other types of flies were obtained from the Bloomington Stock Center.

Generation of p[UAS-DNlg4] transgenic flies. To generate $p[U A S-D N / g 4]$ flies, dnlg4 cDNA was subcloned into a $P U A S T$ vector and injected into $w^{1118}$ flies. The transgene was subsequently crossed into a $w^{1118} ;$ dnlg4 background.

Sleep and circadian analysis. Three- to fiveday-old male flies raised in LD-entrained cultures were placed in $65 \times 5 \mathrm{~mm}$ glass tubes containing $5 \%$ sucrose $2 \%$ agarose. Locomotor activity was measured for $5-7 \mathrm{~d}$ at $25^{\circ} \mathrm{C}$ during LD cycles using DAM5 monitors (Trikinetics) in a DigiTherm CircKinetics incubator (Tritech Research). Data were collected in $1 \mathrm{~min}$ bins, and a sliding window was applied. Sleep was defined as 5 consecutive minutes of inactivity as previously described (Huber et al., 2004). Sleep latency was measured from the time of lights off to the onset of the first sleep episode. Data were analyzed with ClockLab software (Actimetrics).

Antibodies. Anti-DNlg4 antibody was generated in rabbits against a purified glutathione $S$-transferase fusion fragment (aa9121089) of DNlg4 protein, which is encoded by GH07829 cDNA (GenBank Accession Number BT050584). The antibody was purified using an affinity column generated by coupling a DNlg4 fragment (aa912-1089) to Sepharose 4B. Other antibodies were obtained from Millipore (GFP, MAB3580), Cell Signaling Technology (hemagglutinin (HA)-tag, C29F4), and Developmental Studies Hybridoma Bank (PDF, C7, and tubulin, E7).

Immunostaining. Whole-head staining was performed as previously described (Cao et al., 2011; Tian et al., 2013). Briefly, after dissection and fixation, fly heads were stained with antiPDF (1:200) and anti-DNlg4 (1:40) antibodies. Samples were imaged on an LSM 510 confocal microscope (Zeiss).

Electrophysiology. Whole-cell recording was performed as previously described (Sheeba et al., 2008a). Briefly, PDF neurons of wild-type and dnlg4 mutant flies were visualized by membrane expression of a GFPtagged mCD8 using the pdf-Gal4 driver. Flies were maintained under a $12 \mathrm{~h}$ LD cycle, and the brains of 2- to 3-d-old flies were quickly dissected under a light intensity of 4000 lux in external solution. The perineural sheath of the brain was gently removed with fine tweezers. The dissected brains were incubated in standard external solution containing $20 \mathrm{U} / \mathrm{ml}$ papain and $1 \mathrm{~mm}[\mathrm{SCAP}] \mathrm{L}-\mathrm{cysteine}$ at $37^{\circ} \mathrm{C}$ for $10 \mathrm{~min}$, and then transferred to a submersion chamber and fixed with a platinum holder. The chamber was perfused with extracellular recording solution containing the following (in mM): $101 \mathrm{NaCl}, 3 \mathrm{KCl}, 1 \mathrm{CaCl}_{2}, 4 \mathrm{MgCl}_{2}, 5$ glucose, 1.25 $\mathrm{NaH}_{2} \mathrm{PO}_{4}$, and $20.7 \mathrm{NaHCO}_{3}$. The solution was saturated with $95 \%$ $\mathrm{O}_{2} / 5 \% \mathrm{CO}_{2}$ throughout all recordings. For recordings at ZT13-ZT16, dissections were executed under dark conditions except for brain dissection, which was executed under a light intensity of 400 lux for $<90 \mathrm{~s}$.

GFP-expressing 1-LNvs were visualized using an Olympus X51 microscope with a $40 \times$ water-immersion objective. Recording pipettes $(8-10$ $\mathrm{M} \Omega$ ) were filled with solution containing the following (in $\mathrm{mM}$ ): 102 K-gluconate, $0.085 \mathrm{CaCl}_{2}, 1.7 \mathrm{MgCl}_{2}, 17 \mathrm{NaCl}, 0.94$ ethylene glycol tetraacetic acid, and 8.5 HEPES adjusted to $7.3 \mathrm{pH}$ and $235 \mathrm{mOsm}$. Signals
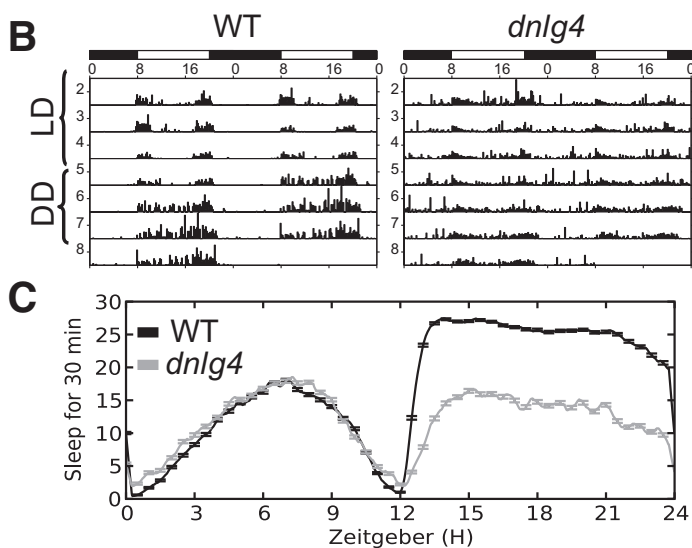

E

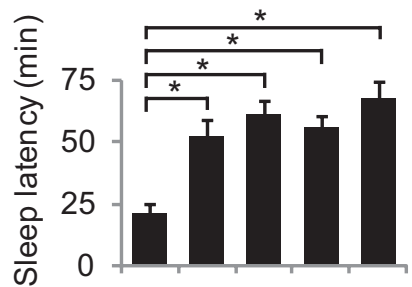

G

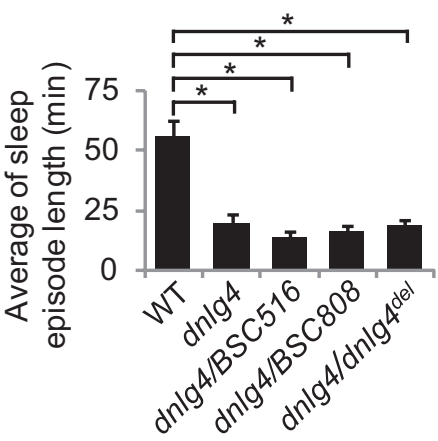

Figure 1. $\quad d n l g 4$ mutant flies show abnormal sleep behavior. $\boldsymbol{A}$, Western blot analysis showing the protein level of DNlg4 in wild-type (WT), dnlg4 mutant, and dnlg4/BSC516 heterozygous mutant flies. Tubulin was used as a loading control. Quantification of relative DNIg4 protein level for each genotype is presented on the bottom. $\boldsymbol{B}$, Representative 7-d locomotor traces of WT (left) ant (right) flies. White areas indicate day, and black areas indicate night. C, Average total sleep per night in WT and dnlg4 mutant flies, plotted as a 30 min moving average. $n=200 . \boldsymbol{D}, \boldsymbol{E}$, Quantification of total sleep time per night and sleep onset latency after lights off for each genotype. $n=200 . F, G$, Quantification of number of sleep episodes per night and average sleep episode length for each genotype; $n=200,{ }^{*} p<0.001$.

were acquired using an Axon-700B amplifier, digitized at $10 \mathrm{kHz}$ by Digidata 1440, and filtered at $2 \mathrm{kHz}$.

Spontaneous firing was recorded in I-clamp mode $(\mathrm{I}=0)$, and $30 \mathrm{~s}$ traces of each recording were analyzed. For measurement of GABA currents, PDF neurons were clamped at $-30 \mathrm{mV}$, and puffs of $0.1,1$, and 10 mM GABA lasting $100 \mathrm{~ms}$ were applied to neurons using a Picospritzer (WPI, PV820). The puffing pipettes were set $\sim 50 \mu \mathrm{m}$ from the neurons. The pressure applied ( $4 \mathrm{psi}$ ) was sufficient to allow GABA to rapidly reach the neurons without producing artifacts. Two sweeps of each cell were pooled to generate the sample traces. For all electrophysiological experiments, $n$ represents the number of neurons, and only one neuron per fly was used.

Drug treatment. For experiments involving carbamazepine (CBZ), a stock solution $(20 \mathrm{mg} / \mathrm{ml})$ of CBZ was dissolved in ethanol and mixed into standard agar medium. After three to four baselines were recorded on standard medium, flies were switched to CBZ/sucrose/agar $5 \mathrm{~h}$ before the onset of the dark period.

Statistical analysis. Data are presented as mean \pm SEM. For statistical analysis of sleep parameters with normal distributions, two-tailed Student's $t$ tests were used to compare genotypes. To analyze sleep episode length, which was not normally distributed, Mann-Whitney $U$ tests were used. Statistical significance was set at $p<0.05$. 


\section{Results}

dnlg4 mutant flies exhibit abnormal sleep behavior

To obtain null mutant dnlg4 (CG34139) flies, we generated a $d n \lg 4^{d e l}$ mutant line using the FRT/FLP-mediated genomic deletion strategy with two FRT-containing Exelixis lines (f01735 and e01254) flanking the $d n \lg 4$ locus. Homozygous $d n l g 4^{d e l}$ deletion is lethal. To get a viable allele for sleep-behavior analysis, we obtained a hypomorphic allele, $p\{F R T\} 2 A, p\{F R T\} 82 B$, $p B a c\{S A s t o p D s R e d\}^{L L 01874}$, which contains two FRT transposons and a piggyBac transposon insert in the region near the stop codon of CG34139. The mutant line was out-crossed (based on the DsRed marker) for more than six generations with the $w^{1118}$ strain to delete the extra FRT transposons and standardize the background. From here on, the pBac\{SAstopDsRed $\}^{L L 01874} \mathrm{mu}-$ tant is referred to as the $d n \lg 4$ mutant. Western blots showed a marked reduction of DNlg4 protein levels in both homozygous and combination $d n l g 4$-deficient flies (Fig. 1A).

To examine the role of DNlg4 in sleep, we assessed sleep behavior in $d n \lg 4$ mutant flies during $12 \mathrm{~h} \mathrm{LD} \mathrm{cycles.} \mathrm{We} \mathrm{found} \mathrm{that}$ dnlg4 mutant flies showed significantly less total night sleep time $(582 \pm 29.9 \mathrm{~min}$ vs $339.8 \pm 11.5 \mathrm{~min}$; Fig. $1 B-D)$ and longer sleep onset latency $(21 \pm 3.7 \mathrm{~min}$ vs $52 \pm 7.2 \mathrm{~min}$; Fig. $1 E)$ compared with wild-type flies. Furthermore, compared with wild-type flies, mutants exhibited more night sleep episodes (10.5 \pm 1.4 vs $17.9 \pm 2.3$; Fig. $1 F)$ with markedly shorter durations (55.7 \pm 6.7 min vs $19.1 \pm 3.8 \mathrm{~min}$; Fig. $1 G$ ), reflecting poorly consolidated night sleep in $d n l g 4$ mutants. Similar results were observed for $d n \lg 4 / d n \lg 4^{d e l}$ combination flies and two additional $d n \lg 4$ deficient flies (Fig. 1D-G) in which the mutant allele was combined with $D f(3 R) B S C 516$ or $D f(3 R) B S C 808$ (both flies lacked the entire $d n \lg 4$ gene). These results indicate that impaired DNlg4 function results in poorly consolidated night sleep, which strongly suggests the involvement of DNlg4 in sleep regulation.

\section{DNlg4 is highly expressed in l-LNvs and required for sleep}

To investigate how DNlg4 regulates sleep, we first examined the expression pattern of endogenous DNlg4 in the adult brain using an anti-DNlg4 antibody. In wild-type flies, strong immunostaining was observed in LNvs, identified by double staining with anti-PDF antibody (Renn et al., 1999; Fig. 2A). DNlg4 staining was also observed in fan-shaped body neurons and other unidentified neurons (Fig. 2A). In LNvs, DNlg4 was located in somata and also appeared as puncta in the terminals of the accessory medulla (Fig. $2 B$ ). In $d n l g 4$ mutant flies, both overall and LNv terminal immunostaining was significantly reduced (Fig. $2 A-C$ ), consistent with Western blot results. Interestingly, somata of small LNvs (s-LNvs) were weakly labeled, but somata of l-LNvs, as identified with the c929-Gal4 driver (Taghert et al., 2001), were strongly labeled by anti-DNlg4 staining (Fig. 2D,E). To further investigate the subcellular localization of DNlg4 in l-LNv somata, we labeled LNv membranes with mCD8-GFP and stained with an antiDNlg4 antibody. Surprisingly, DNlg4 was mostly located in intracellular regions (Fig. $2 F$ ). To further display the organellar distribution of endogenous DNlg4, we stained the LNvs, whose endoplasmic reticulum (ER) or Golgi had been labeled with GFP. The results showed that DNlg4 predominately exists in the Golgi (Fig. 2G,H).

To map the anatomical requirements of DNlg4 for sleep, we directed RNAi against DNlg4 using the Gal4/UAS system. More than 10 Gal4 drivers with targeted expression in various regions of the nervous system were tested. RNAi against DNlg4 using several Gal4 divers with complicated expression patterns (e.g., pan-neuronal elav-Gal4, Rdl-Gal4, c929-Gal4, 117y-Gal4, and cry-Gal4) led to lethality. However, both $p d f$-Gal4 and per-Gal4 drivers recapitulated the sleep defects observed in $d n \lg 4$ mutant
A

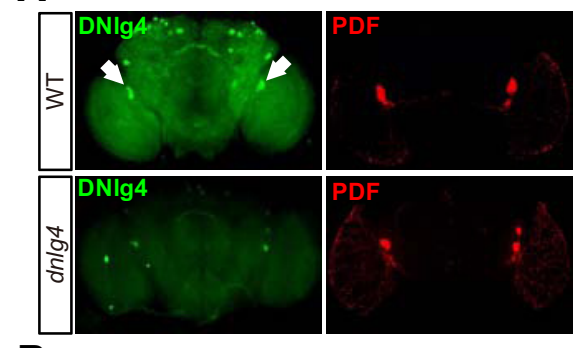

B

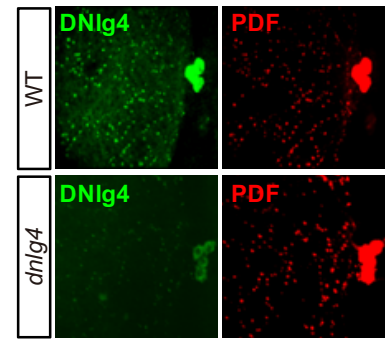

D

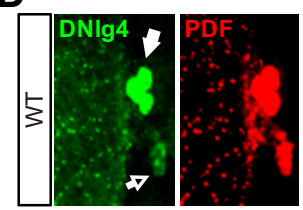

$\mathbf{F}$

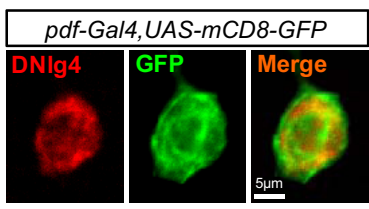

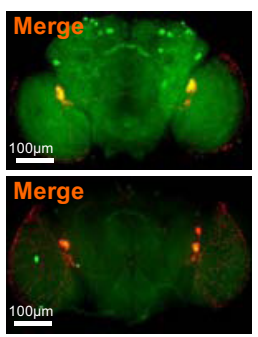

C
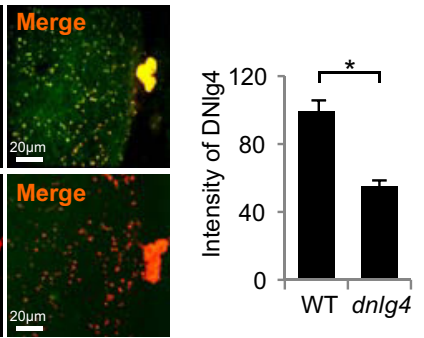

E
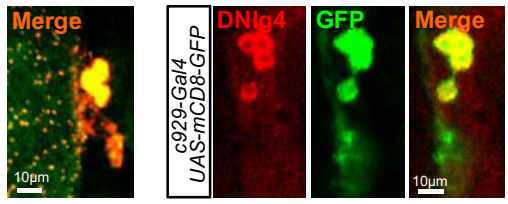

G

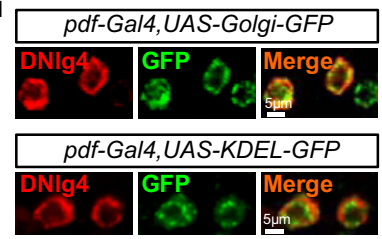

Figure 2. DNIg4 is highly expressed in I-LNvs. $\boldsymbol{A}$, Immunostaining images indicating the expression pattern of DNIg4. PDF neurons are indicated by arrows. Scale bar, $100 \mu \mathrm{m}$. $\boldsymbol{B}$, Distribution of DNlg4 in LNv terminals. Scale bar, $50 \mu \mathrm{m}$. $\boldsymbol{A}, \boldsymbol{B}$, Dissected whole brains were stained with anti-DNIg4 (green) and anti-PDF (red) antibodies. C, Quantification of relative DNlg4 protein amount in LNvs for each genotype. D, DNlg4 was highly expressed in I-LNvs. LNvs were labeled with mCD8-GFP under the control of the $p d f$-Gal4 driver. I-LNvs are indicated by the closed arrow, and s-LNvs are indicated by the open arrow. Scale bar, $10 \mu \mathrm{m}$. $\boldsymbol{E}$, I-LNvs were labeled with mCD8-GFP under control of the $929-G a l 4$ driver. Scale bar, $10 \mu \mathrm{m}$. F, DNlg4 was located in the intracellular region of I-LNv somata. I-LNv somata membranes were labeled with mCD8-GFP under the control of the pdf-Gal4 driver. Scale bar, $5 \mu \mathrm{m}$. G, In pdf-Gal4/ $p$ [UASHgalactosyltransferase-GFP] flies, DNIg4 colocalized with the GFP signal. Dissected LNvs were costained with DNlg4 antibody (red) and GFP antibody (green, showing Golgi). Scale bar, 5 $\mu \mathrm{m} . \boldsymbol{H}$, In pdf-Gal4/p[UASHGFP-KDEL] flies, DNlg4 did not colocalize with GFP-KEDL. Dissected LNvs were costained with DNlg4 antibody (red) and GFP antibody. Scale bar, $5 \mathrm{~mm}$. WT, wild type.

flies (Fig. 3A-E), with other drivers only slightly affecting sleep (Fig. $3 A, B$ ). Immunostaining showed that $p d f$-Gal4 RNAi specifically repressed DNlg4 expression in PDF neurons (Fig. $3 F, G$ ). Together, these results indicate that PDF neuron-expressed $\mathrm{DNlg} 4$ is involved in sleep regulation.

Next, we generated $p[U A S-D N \lg 4]$ flies and conducted rescue experiments to validate the anatomical requirements of DNlg4 for sleep. Sleep defects, especially those in early evening sleep, were restored in $d n \lg 4$ mutant flies through expression of DNlg4 in 1-LNvs using $p d f$-Gal4 or $c 929-G a l 4$ drivers (Fig. $4 A-E$ ). However, we failed to rescue sleep defects using other drivers with more restricted neuronal expression, including 104y-Gal4 expressed in fan-shaped body neurons (Young and Armstrong, 2010; Fig. 4A, B). Therefore, DNlg4 is highly expressed in l-LNvs, and l-LNv-derived DNlg4 is essential for early evening sleep. 
A

B

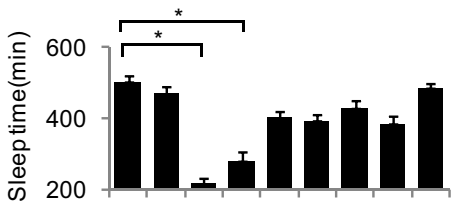

C

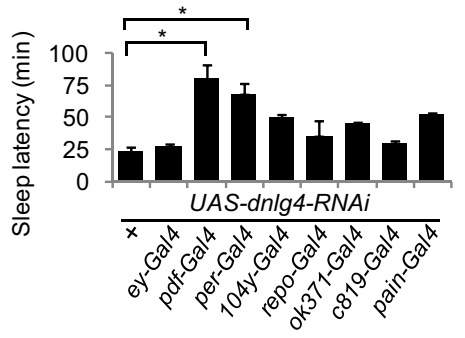

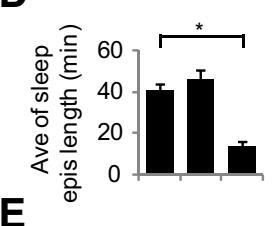

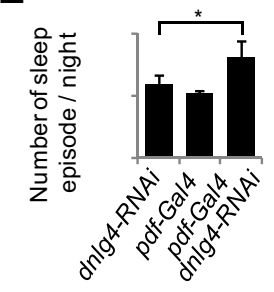

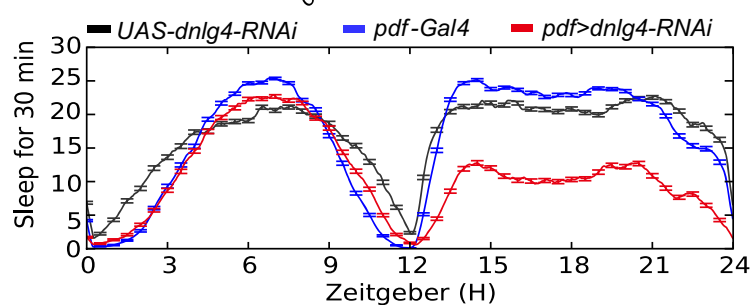

$\mathbf{F}$

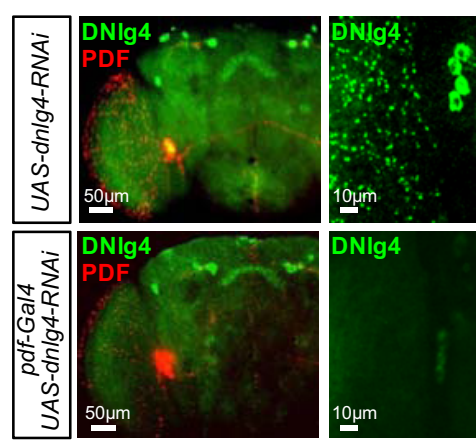

G

Figure 3. Depletion of DNIg4 in I-LNvs leads to abnormal sleep. $\boldsymbol{A}, \boldsymbol{B}$, Total night sleep and sleep onset latency in flies with depletion of DNIg4 using UAS-dnlg4-RNAi driven by anatomically restricted Gal 4 drivers. For each Gal 4 line, a single copy of the Gal 4 driver was used for the test; $n=32,{ }^{*} p<0.001$ for RNAi versus control flies. C, Average sleep traces for UAS-nlg4RNAi;pdf-Gal 4 and control flies, plotted as a 30 min moving average; $n=32 . \boldsymbol{D}, \boldsymbol{E}$, Quantification of average sleep episode length and number per night in UAS-nlg4-RNAi;pdf-Gal4 and control flies; $n=32,{ }^{*} p<0.001$ for UAS-nlg4-RNAi;pdf-Gal4 versus control flies. $\boldsymbol{F}$, Expression of DNIg4 in UAS-nlg4-RNAi;pdf-Gal4 (bottom) and control (top) flies. Dissected whole brains were stained with anti-DNlg4 (green) and anti-PDF (red) antibodies. Scale bar, $50 \mu \mathrm{m}$. Note that DNlg4 distribution in UAS-nlg4-RNAi;pdf-Gal4 flies is comparable to control flies except in PDF neurons. Enlarged images showing expression of DNIg4 in PDF neurons are presented on the right. Scale bar, $10 \mu \mathrm{m}$. G, Quantification of relative DNIg4 protein amount in LNvs for each genotype.

Knock-down of DNlg4 expression in adult flies reduces night sleep

The abnormal sleep observed in dnlg4 mutant flies could be due to developmental deficits in larva or impaired DNlg4 function in adults. To distinguish between these possibilities, we generated UAS-dnlg4-RNAi;tubulin-Gal80 ${ }^{t_{s}} / p d f-G a l 4$ flies and assessed their sleep behavior. In these flies, RNAi was suppressed during development by the ubiquitous expression of temperaturesensitive $\mathrm{Gal} 80^{\text {ts }}$ but selectively induced by exposure to a temperature of $30^{\circ} \mathrm{C}$ (McGuire et al., 2004). Flies were reared at $21^{\circ} \mathrm{C}$ for their entire development. As adults, flies were entrained for $3 \mathrm{~d}$ of $\mathrm{LD}$ at $21^{\circ} \mathrm{C}$, switched to $30^{\circ} \mathrm{C}$ for $2.5 \mathrm{~d}$, and then shifted back to $25^{\circ} \mathrm{C}$. Immunostaining revealed that DNlg4 protein levels were reduced after UAS-dnlg4-RNAi;tubulin-Gal80 ${ }^{t_{s}} /$ pdf-Gal4 flies were switched to $30^{\circ} \mathrm{C}$ for $24 \mathrm{~h}$ (Fig. $5 \mathrm{~A}, \mathrm{~B}$ ). Compared with con-

A

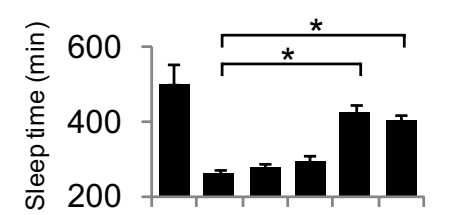

B

产
$\frac{0}{0}$
$\frac{\bar{d}}{0}$
$\frac{0}{0}$
$\frac{\Phi}{\omega}$
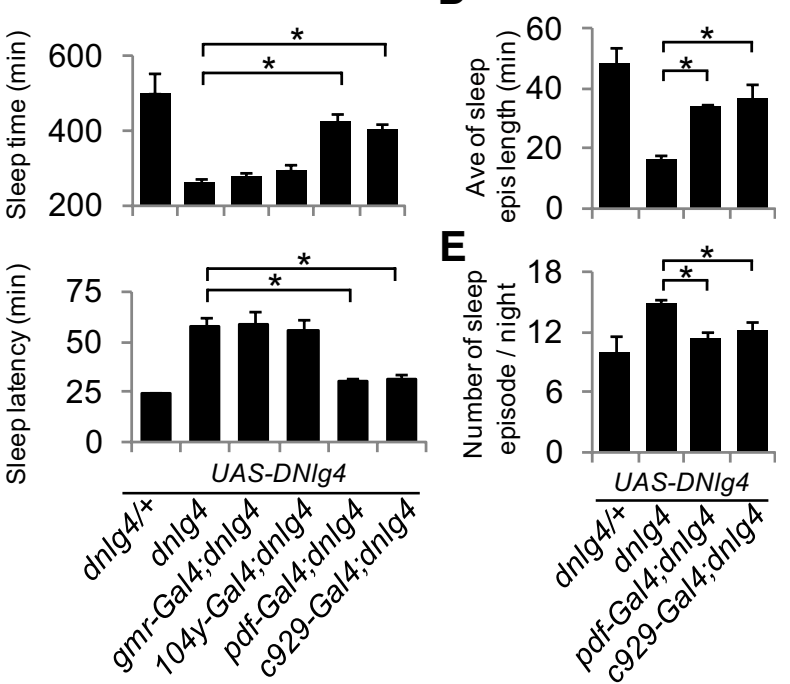

C

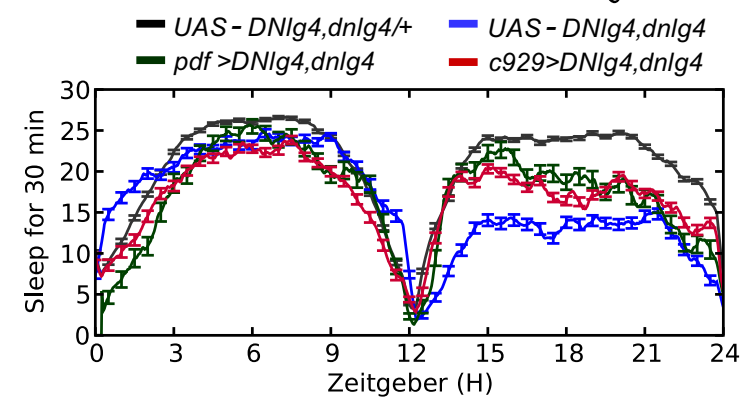

E

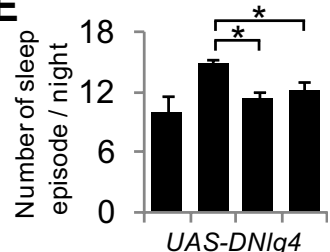

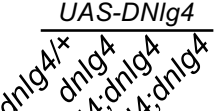
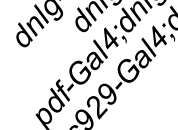

$3^{2}$

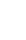

\section{- UAS-DNIg4,dnlg4}

Figure 4. Specific expression of DNIg4 in I-LNvs rescues defective sleep in $d n / g 4$ mutant flies. $\boldsymbol{A}, \boldsymbol{B}$, Total night sleep and sleep onset latency in flies with rescued DNIg4 expression using anatomically restricted Gal4 drivers. Flies bear one copy of the indicated drivers; $n=32,{ }^{*} p<0.001$ for rescued versus $d n l g 4$ mutant flies. $C$, Average sleep traces for rescued and control flies, plotted as a 30 min moving average; $n=32$. D, $\boldsymbol{E}$, Quantification of average sleep episode length and number per night in rescued and control flies. $n=32$. * indicates $p<0.001$ for rescued vs control flies.

trol flies, UAS-dnlg4-RNAi tubulin-Gal80 $0^{t s} / p d f-G a l 4$ flies exhibited a progressive delay of sleep onset latency after switching to $30^{\circ} \mathrm{C}$ (Fig. $5 C, D$; Fig. $5 C$ shows a continuous trace of sleep behavior starting on the last day of entrainment). Two days after shifting back to $25^{\circ} \mathrm{C}, U A S$-dnlg4-RNAi tubulin-Gals $0^{t s} / p d f$-Gal4 flies still showed longer sleep onset latency and less total night sleep time, whereas control flies exhibited normal sleep behavior (Fig. $5 E-H)$. These findings demonstrate that knock-down DNlg4 expression in adult flies is sufficient to reduce night sleep.

\section{GABA transmission is impaired in mutant l-LNvs}

PDF is secreted by LNvs and acts as a major regulator of sleep in Drosophila (Parisky et al., 2008). The electrical activity of l-LNvs is circadian-regulated (Sheeba et al., 2008a) and LNv-hyperexcited flies exhibits a PDF-mediated reduction in sleep quantity and quality (Sheeba et al., 2008b). We conducted whole-cell current-clamp recordings of l-LNvs to determine their electrophysiological properties. We dissected flies that were entrained in different conditions and performed whole-cell recording of l-LNvs with various recording buffers. 1-LNvs fired spontaneous action potentials (APs), with firing patterns heavily influenced by entrainment condition and recording buffer. Using previously established recording conditions (Sheeba et al., 2008a), we found that l-LNvs from dnlg4 mutant flies showed similar electrophysiological properties as those from wild-type flies during the day (ZT2-ZT5, 
A

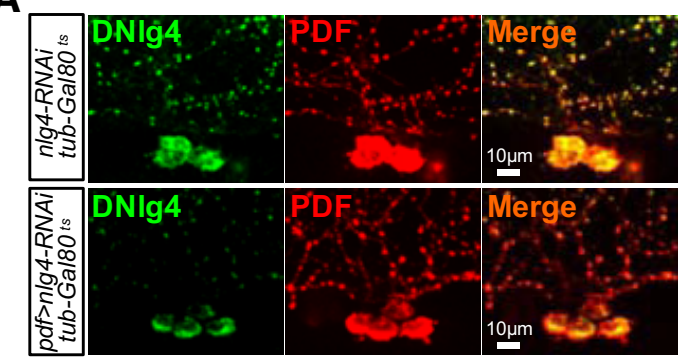

B

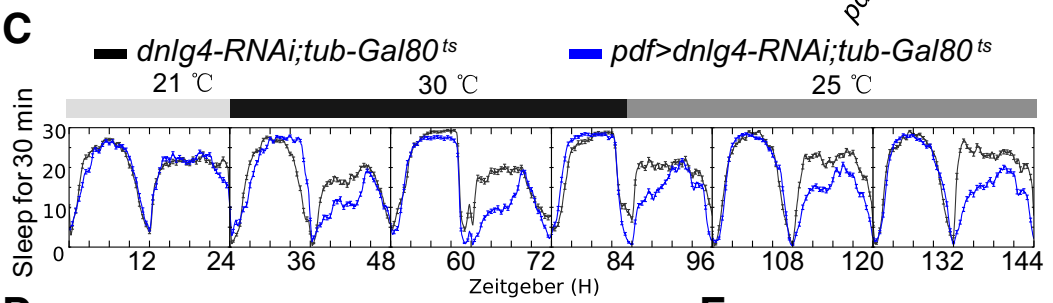

D

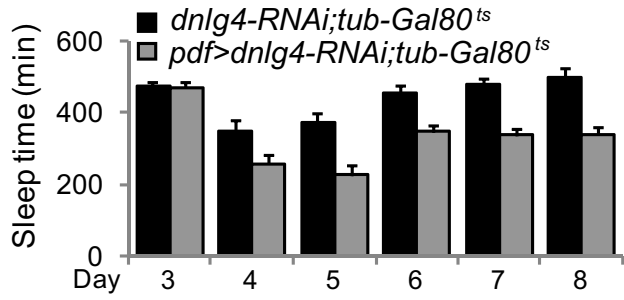

\section{E}

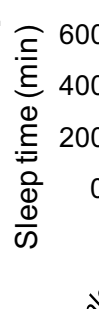

$\mathbf{F}$

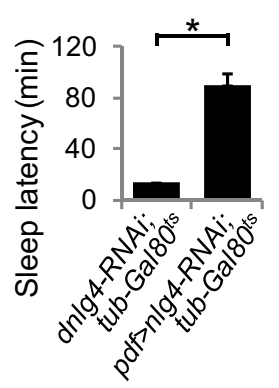

G

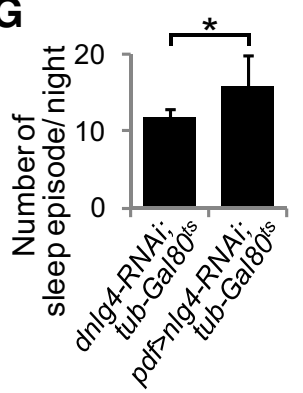

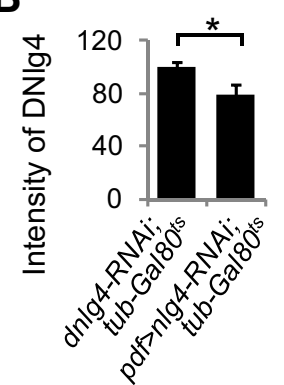

$25{ }^{\circ} \mathrm{C}$
$\mathbf{H}$

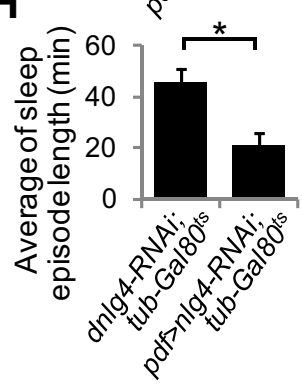

Figure 5. Sleep behavior of UAS-dnIg4-RNAi;tubulin-Gal80ts /pdf-Gal4 flies. A, Immunostaining images showing DNIg4 protein levels in UAS-dnlg4-RNAi;tubulin-Gal80 $0^{\text {ts }} /$ pdf-Gal4 (bottom) and control (top) flies. Dissected whole brains were stained with anti-DNlg4 (green) and anti-PDF (red) antibodies. Scale bar, $10 \mu \mathrm{m}$. B, Quantification of relative DNIg4 protein amount in LNvs for each genotype is presented on the right. $\boldsymbol{C}$, Continuous sleep measurements of flies expressing the dnlg4-RNAi and temperaturesensitive Gal $80{ }^{\text {ts }}$ in PDF neurons. Entrainment temperatures are shown at the top; $n=32 . D$, Quantification of total sleep time for individual nights. $E$, Average total sleep time per night in each condition. $F$, Quantification of sleep onset latency after lights off for each condition. $\mathbf{G}, \boldsymbol{H}$, Quantification of sleep episode number and average length. $\mathbf{D}-\mathbf{G}, n=32$, and values for day 7 and 8 are quantified and presented. ${ }^{*} p<0.001$ for UAS-dnlg4-RNAi;tubulin-Gal80 ${ }^{\text {ts }} /$ pdf-Gal 4 versus UAS-dnlg4-RNAi /pdf-Gal4 flies.

with ZT0 denoting the time that lights were turned on), with tonic spontaneous AP firing and frequent spike bursts (6/8 wildtype cells and 8/9 mutant cells; Fig. 6A). At ZT13-ZT16, wildtype 1-LNvs showed reduced activity consisting of tonic spontaneous AP firing and rare bursts (10/10 cells; Fig. 6A), whereas most $d n l g 4$ mutant l-LNvs showed high activity consisting of tonic spontaneous AP firing and frequent bursts ( $7 / 9$ cells; Fig. 6A). At ZT13-ZT16, wild-type and dnlg4 mutant l-LNvs showed comparable firing amplitudes but significant differences in percentage of spikes fired in bursts, frequency of firing, and resting membrane potential (Fig. $6 B-E$ ). Therefore, 1-LNvs in dnlg4 mutants are hyperactivated at night.

1-LNv activity is suppressed at night by inhibitory neurotransmitters such as GABA (Shang et al., 2008; Sheeba et al., 2008b; Sehgal and Mignot, 2011). Furthermore, the $\mathrm{GABA}_{\mathrm{A}}$ receptor RDL is expressed in 1-LNvs and promotes sleep in Drosophila (Parisky et al., 2008; Chung et al., 2009). We found that puffing GABA (10 $\mathrm{mM}, 100 \mathrm{~ms}$ ) on l-LNvs resulted in a hyperpolarized resting membrane potential and blockade of spontaneous AP firing (Fig. $6 F$ ), suggesting that l-LNv hyperactivity in dnlg4 mutants could be due to impaired GABA transmission. To address this possibility, we directly measured GABA receptormediated currents in l-LNvs. A Picospritzer was used to puff different concentrations of GABA $(0.1,1$, and $10 \mathrm{~mm})$ on l-LNvs that were voltage clamped at $-30 \mathrm{mV}$. Wildtype l-LNvs did not exhibit detectable currents after puffing $0.1 \mathrm{~mm}$ GABA (data not shown). GABA currents were slightly increased after puffing $10 \mathrm{~mm}$ GABA compared with $1 \mathrm{~mm}$ GABA, but this difference was not significant (Fig. $6 G$ ). By puffing 10 mM GABA, we recorded saturated GABAgated outward currents that were blocked by $\mathrm{GABA}_{\mathrm{A}}$ receptor inhibitor picrotoxin (PTX, $200 \mu \mathrm{M}$; Fig. 6H). At night, dnlg4 mutant l-LNvs showed significantly reduced GABA currents compared with wild-type l-LNvs (peaking at $23.16 \pm 2.16 \mathrm{pA}$ vs $68.45 \pm 8.91$ pA; Fig. $6 H, I)$. These results demonstrate that GABA transmission is largely impaired in $d n \lg 4$ mutant flies.

\section{Impaired GABA transmission in} mutant 1-LNvs leads to sleep defects We next investigated whether the sleep defects observed in dnlg4 mutant flies are due to impaired GABA transmission. If sleep defects are due to impaired GABA transmission, then normal sleep should be restored by increasing RDL channel currents. The hypomorphic mutation $\mathrm{RDL}^{\mathrm{A} 302 \mathrm{~S}}$ specifically decreases the rate of RDL desensitization with little or no effect on other channel properties (Zhang et al., 1994). As a consequence, the mutant receptor has a longer single-channel open duration, which increases RDL channel currents (Agosto et al., 2008). By introducing the mutant $\mathrm{RDL}^{\mathrm{A} 302 \mathrm{~S}}$ channel into the dnlg4 mutant background, we successfully restored night sleep (Fig. $7 A-C$ ), indicating that the sleep defects observed in dnlg4 mutants are due to impaired GABA transmission. To further support this conclusion, we also performed pharmacological experiments with CBZ, which accelerates RDL desensitization and inhibits night sleep in a dose-dependent manner (Agosto et al., 2008). We found that $0.5 \mathrm{mg} / \mathrm{ml} \mathrm{CBZ} \mathrm{significantly} \mathrm{inhibited}$ night sleep in wild-type flies but did not further inhibit night sleep in dnlg4 mutant flies (Fig. 7D-F). A higher dose of CBZ (1 $\mathrm{mg} / \mathrm{ml}$ ), however, might further suppress night sleep in dnlg4 mutants (Fig. $7 D-F$ ), as GABA transmission was not completely blocked in mutant flies (Fig. $6 \mathrm{H}, \mathrm{I}$ ). Together, these results indicate that $\mathrm{DNlg} 4$ regulates sleep behavior through modulating GABA transmission. 
A
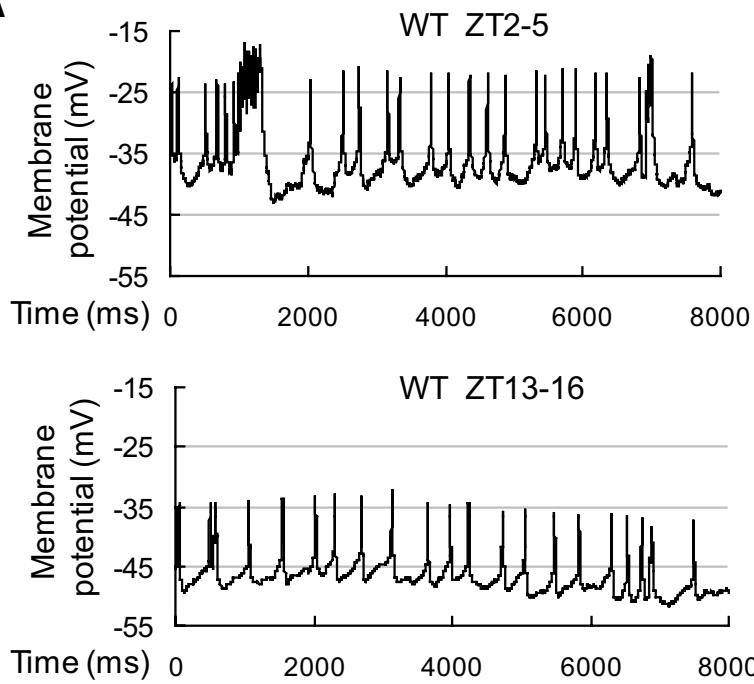
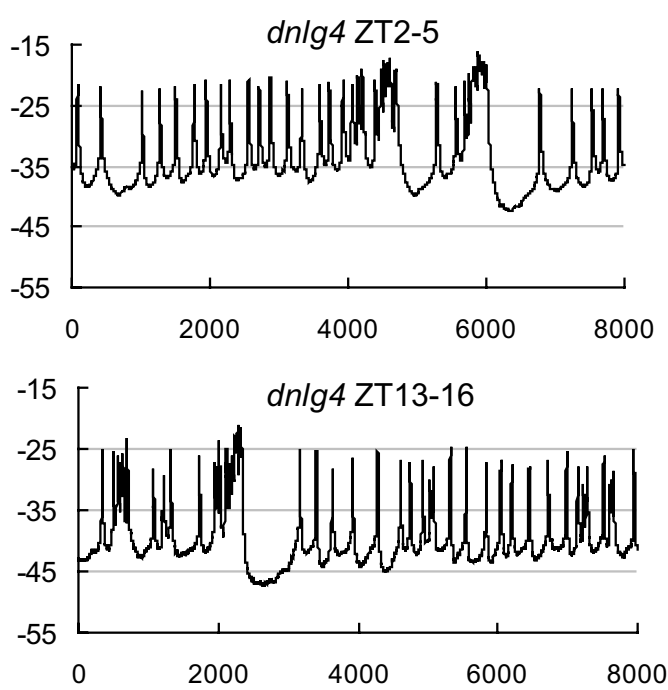

B

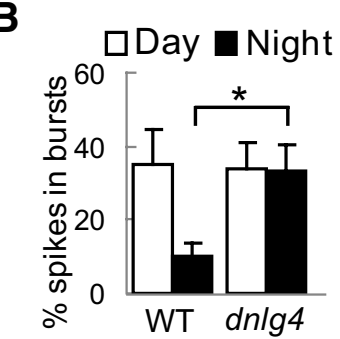

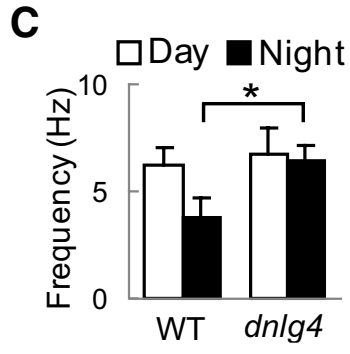

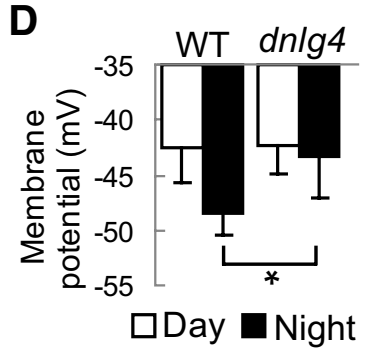

E

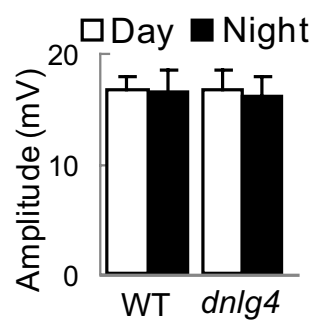

$\mathbf{F}$

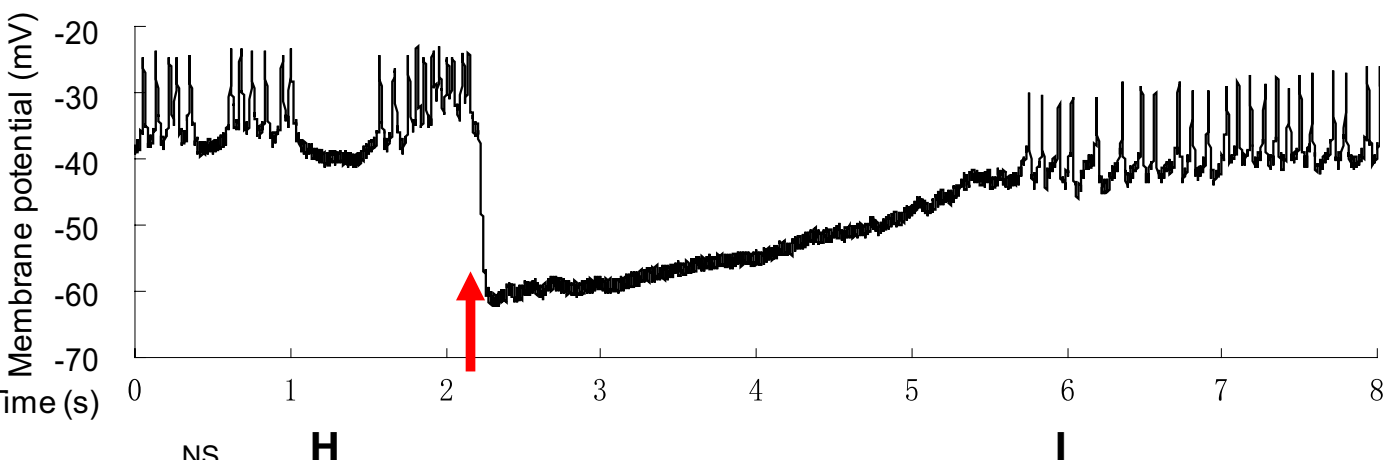

G

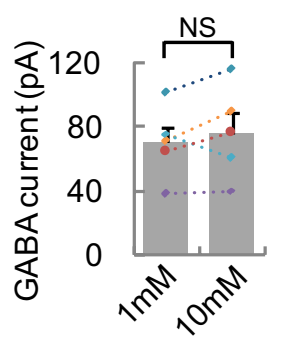

H

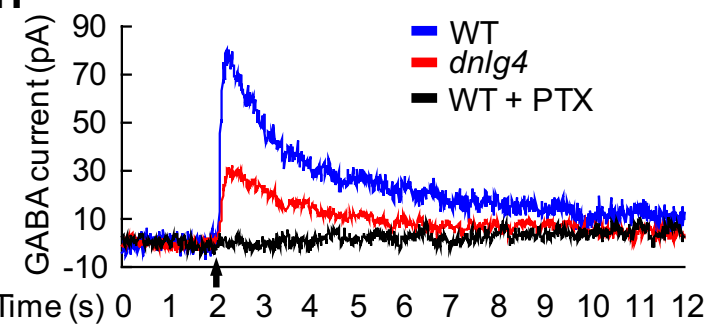

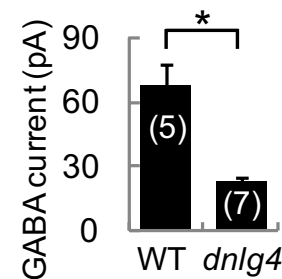

Figure 6. GABA transmission is impaired in $d n l g 4$ mutant I-LNvs. A, Representative whole-cell recording traces from wild-type (WT) and dnlg4 mutant I-LNvs at day and night. B, Percentage of spikes fired in bursts in WT and dnlg4 mutantI-LNvs. C, Average frequency of spontaneous AP firing. $\boldsymbol{D}$, Average resting membrane potentials for each genotype and condition. $\boldsymbol{E}$, Average spike amplitude for each genotype and condition. $\boldsymbol{B}-\boldsymbol{E}, n=9$ for WT daytime, $n=10$ for WT nighttime, $n=9$ for dnlg4 daytime, $n=8$ for dnlg 4 nighttime, ${ }^{*} p<0.05$ for WT versus dnlg 4 mutant I-LNvs. $F$, GABA puffing on I-LNvs hyperpolarizes resting membrane potential and blocks spontaneous AP firing. PDF neurons were held in 1 -clamp $(I=0)$ and puffs of $10 \mathrm{~mm} G A B A$ lasting $100 \mathrm{~ms}$ were applied. Arrow indicates the time point of GABA puffing. $n=6 . G$ GABA-gated currents with puffing of 1 and $10 \mathrm{~mm}$ GABA on five individual WTI-LNvs. Averaged GABA currents with puffing of 1 and $10 \mathrm{~mm}$ are also presented. $\boldsymbol{H}$, Representative responses ofWT (blue) and mutant(red) I-LNvs to applications of $10 \mathrm{~mm} \mathrm{GABA} \mathrm{puffs} \mathrm{in} \mathrm{the} \mathrm{presence} \mathrm{(black)} \mathrm{and} \mathrm{absence} \mathrm{of} 200 \mu \mathrm{mPTX}$. The time point of GABA puffing is indicated by an arrow. I, The averaged GABA currents in WT and dnlg4 mutant I-LNvs. The number of I-LNvs for each genotype and condition are indicated. ${ }^{*} p<0.001$ for WT versus dnlg4 mutant I-LNvs.

DNlg4 regulates RDL clustering through associations with RDL in vivo

RDL puncta in 1-LNv varicosities represent synaptic inputs to l-LNvs (Chung et al., 2009). To further reveal how DNlg4 regulates GABA transmission in l-LNvs, we first examined the num- ber of varicosities formed by l-LNvs in the optic lobe. Dendrite branches of LNvs were labeled with mCD8-GFP (membranetethered GFP), and varicosities were marked using anti-PDF staining. In wild-type flies, dendrite branches of 1-LNvs regularly covered the optic lobe, with varicosities formed along each 
A

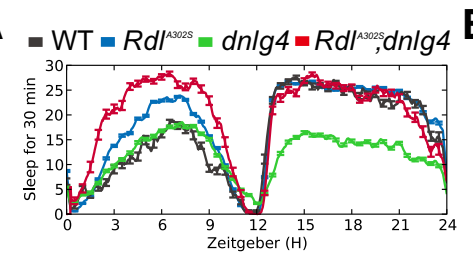

D
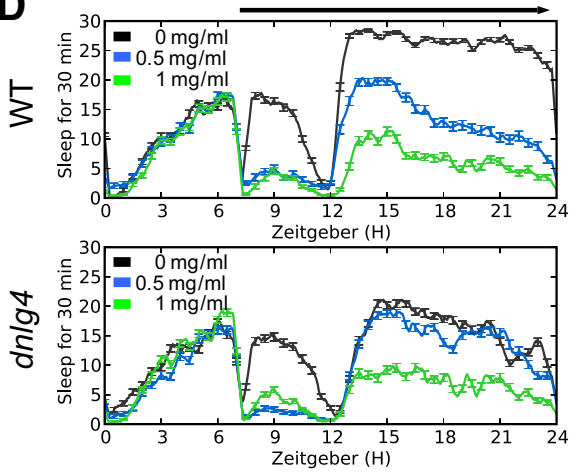

C

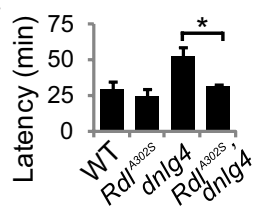

E

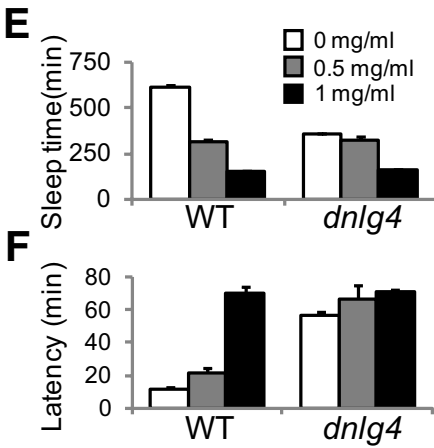

Figure 7. Impaired GABA transmission leads to defective sleep in dnlg4 mutant flies. $\boldsymbol{A}$, Average sleep traces for wild-type (WT), $d n l g 4, R d l^{A 302 S}$, and $R d f^{A 302 S}$, dnlg4 flies plotted as a 30 min moving average, $n=32$. B, C, Quantification of total sleep time and sleep onset latency after lights off for each genotype; $n=32,{ }^{*} p<0.001$ for $d n l g 4$ mutant versus $R d{ }^{A 3025}$, dnlg4 double mutant flies. $D$, Effect of different CBZ concentrations on the sleep pattern of WT (top) and dnlg4 mutant (bottom) flies during the first day of drug treatment: $n=32$; blue, $0.5 \mathrm{mg} / \mathrm{ml}$; green, $1 \mathrm{mg} / \mathrm{ml}$. Black arrow at top of graph indicates CBZ application. $\boldsymbol{E}, \boldsymbol{F}$, Quantification of total sleep time and sleep onset latency after treatment with different CBZ concentrations, $n=32$.

branch (Fig. 8A). In contrast, in dnlg4 mutant flies, l-LNv dendrite branches were distributed in a disordered fashion (Fig. $8 A$ ). Furthermore, $d n \lg 4$ mutant flies had a fewer varicosities in the optic lobe compared with wild-type flies (Fig. $8 A, B$ ).

Next, we investigated the distribution and amount of RDLs in 1-LNv terminals. Due to a lack of specific anti-RDL antibody, we expressed HA-tagged RDL under the $p d f$-Gal4 driver to mimic endogenous RDL. Expression of RDL-HA existed in most l-LNv varicosities in wild-type flies but was present in only $\sim 73 \%$ of varicosities in dnlg4 mutant flies (Fig. $8 C, D$ ). Furthermore, in dnlg4 mutants, RDL-HA signals were sharply reduced in each varicosity as a result of their accumulation in l-LNv somata (Fig. $8 C, E, F)$. These results suggest that DNlg4 is required for RDL clustering in 1-LNvs. As DNlg4 and RDL are similarly distributed in l-LNvs, it is possible that DNlg4 regulates RDL clustering through associations with RDL. To test this possibility, we performed immunoprecipitation experiments and demonstrated that DNlg4 associates with RDL in vivo (Fig. 8G).

\section{Discussion}

Sleep is an essential and evolutionarily conserved behavior. Mounting evidence suggests that sleep in a diverse array of animals is regulated by conserved molecular mechanisms that have not yet been identified. Here, we demonstrated that DNlg4 regulates sleep through modulating $\mathrm{GABA}_{\mathrm{A}}$ receptor $\mathrm{RDL}$ clustering and GABA transmission. This study provides the first evidence that DNlg4 modulates the function of inhibitory synapses and regulates sleep in Drosophila.

\section{Expression of DNlg4 in LNvs}

Immunostaining revealed that DNlg4 was highly expressed in 1-LNvs. Previous genechip data showed that $d n \lg 4$ mRNA levels oscillate in l-LNvs (Kula-Eversole et al., 2010). As dnlg4 mRNA levels in 1-LNvs are significantly reduced in per $^{01}$ mutant flies compared with wild-type flies (Kula-Eversole et al., 2010), the cycling of $d n \lg 4$ mRNA might be under circadian control. Indeed, we found seven E-box elements in the promoter region of the $d n \lg 4$ gene. Recent research showed that the expression profile of Nlg1 oscillates in mice and that the clock transcription factor, BMAL1 and CLOCK, can bind to one E-box located 653 bp before the Nlg1 transcription start site (El Helou et al., 2013). Considering that dnlg4 mRNA levels oscillate in l-LNvs, DNlg4 protein in 1-LNvs might undergo rapid synthesis and degradation similar to these clock genes. The present study provides two lines of evidence to support this speculation. First, we found that DNlg4 colocalized with ER/Golgi-export machinery in l-LNv somata, suggesting that DNlg4 is constantly synthesized and transported. Second, DNlg4 protein level was reduced in RNAi flies after turning the RNAi effect on for $24 \mathrm{~h}$, suggesting that DNlg4 is not stable and may undergo rapid degradation in 1-LNvs. These processes of DNlg4 synthesis and degradation in l-LNvs are worthy of further investigation.

Our immunostaining reveals that DNlg4 was also expressed in fan-shaped body neurons and some unidentified neurons. In our rescue experiments, expression of $U A S-D N l g 4$ with either $c 929-G a l 4$ or $p d f$-Gal4 drivers only partially rescued the sleep defects in $d n l g 4$ mutant flies, especially during early evening sleep. This result is consistent with our observation of a progressive delay in sleep onset after turning on RNAi effects in UAS-dnlg4-RNAi;tubulin-Gal80 ${ }^{\text {ts }} / p d f$-Gal4 flies. A similar increase in wakefulness during the early night has been observed in l-LNv hyperexcited flies (Parisky et al., 2008), suggesting that persistent l-LNv firing increases wakefulness but that the effects are larger at the beginning than at the end of night. Therefore, sleep circuits downstream of l-LNvs and unknown wake-promoting neurons may be gated differentially over the course of the night.

Although fan-shaped body neurons function to promote sleep in Drosophila (Joiner et al., 2006; Pitman et al., 2006; Donlea et al., 2011; Ueno et al., 2012), we found no effects of manipulating DNlg4 expression level in fan-shaped body neurons on sleep. One explanation is that GABA signaling in the fan-shaped body may have a minor role in promoting sleep. Indeed, fan-shaped body neurons only moderately express $\mathrm{GABA}_{\mathrm{A}}$ receptors (Parisky et al., 2008), and dopaminergic signals to the dorsal fan-shaped body have been found to promote arousal in Drosophila (Liu et al., 2012; Ueno et al., 2012). Given that DNlg4 is also expressed in some unidentified neurons, we cannot exclude the possibility that these neurons may have a role in sleep. To fully address these questions, unidentified DNlg4-positive neurons should be characterized and their potential roles in sleep regulation should be directly investigated.

\section{Neuroligins regulate sleep in Drosophila}

Our anatomically restricted manipulations of DNlg4 lead us to conclude that its expression within l-LNvs is essential for normal sleep, which is further supported by our immunostaining results. l-LNvs but not s-LNvs mediate light-driven arousal through the release of PDF neuropeptide (Parisky et al., 2008; Sheeba et al., 2008b), which acts as an arousal-promoting molecule with a 
function similar to orexin in mammals (Chemelli et al., 1999; Lin et al., 1999). PDF release is controlled by l-LNv activity, with higher firing rates during the day and lower firing rates at night (Sheeba et al., 2008a). Electrophysiological recordings revealed that $d n \lg 4$ mutant $1-\mathrm{LNvs}$ showed normal firing rates during the day but maintained daytime firing rates at night, consistent with a previous study showing that LNv-hyperexcited flies display increased arousal and decreased sleep, especially at night (Sheeba et al., 2008b). Thus, alterations of l-LNv activity correlate with changes in sleep behavior in dnlg4 mutant flies.

GABA is an inhibitory neurotransmitter that is thought to promote sleep in mammals (Pace-Schott and Hobson, 2002). Here, we provide solid evidence that GABA transmission in l-LNvs is impaired in $d n \lg 4$ mutant flies. 1-LNvs are light-activated neurons (Sheeba et al., 2008a; Fogle et al., 2011), with activity suppressed at night by GABA signaling (Shang et al., 2008; Sheeba et al., 2008b; Sehgal and Mignot, 2011). Therefore, impaired GABA transmission results in l-LNvs exhibiting daytime firing rates at night, leading to defective sleep in $d n \lg 4$ mutant flies. The $\mathrm{GABA}_{\mathrm{A}}$ receptor $\mathrm{RDL}$ is expressed in 1-LNvs (Parisky et al., 2008; Chung et al., 2009), and the number of RDLs appears to be important for sleep regulation. Downregulation of RDLs in LNvs decreases total night sleep time and increases sleep onset latency (Parisky et al., 2008; Chung et al., 2009). Conversely, overexpression of RDLs specifically in PDF neurons increases total sleep time and increases sleep onset latency (Parisky et al., 2008; Chung et al., 2009). Here, we showed that RDL density in 1-LNv terminals was reduced in $d n \lg 4$ mutants. Therefore, impaired GABA transmission in dnlg4 mutants appears to be due to a reduced RDL density in l-LNv terminals.

All Nlg homologs are expressed in the hypothalamus of rodents and primates (Varoqueaux et al., 2004, 2006; Mungenast and Ojeda, 2005). The evolutionarily conserved sleep regulatory machinery (Sehgal and Mignot, 2011) and molecular functions of Nlgs across different species (Varoqueaux et al., 2006; Szatmari et al., 2007; Banovic et al., 2010; Sun et al., 2011) suggest that mammalian Nlgs may play an important role in sleep regulation. A recent study showed that nlg1 knock-out mice are not able to sustain wakefulness and spend more time in nonrapid eye movement sleep than wild-type mice (El Helou et al., 2013). Our studies further demonstrate that DNlg4 regulates night sleep through modulating GABA transmission. In mam-

A

C

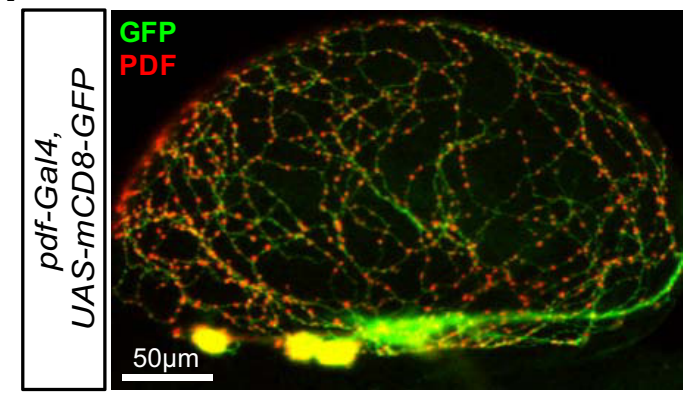

B
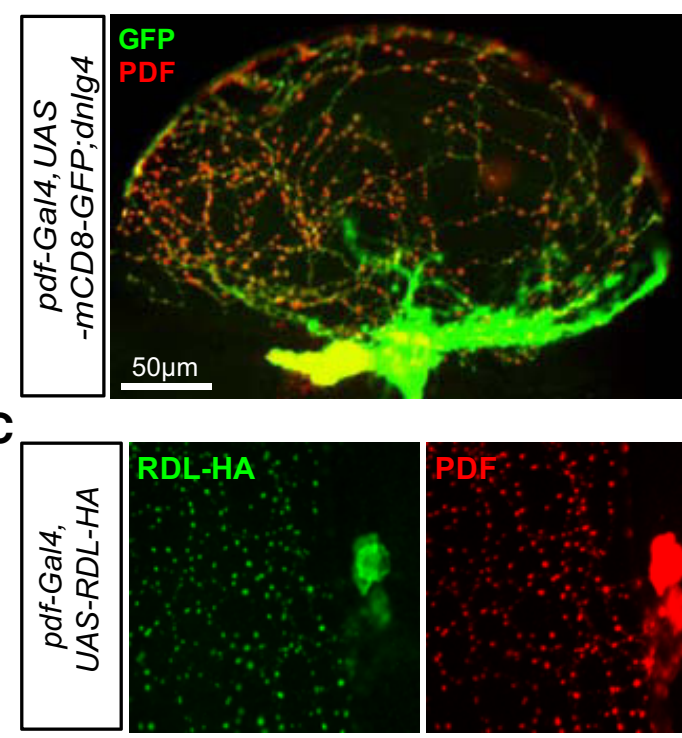

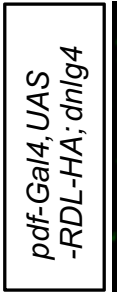

D

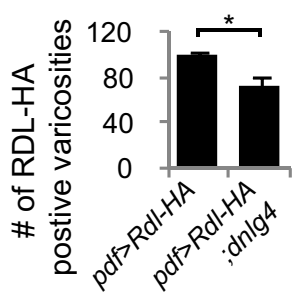

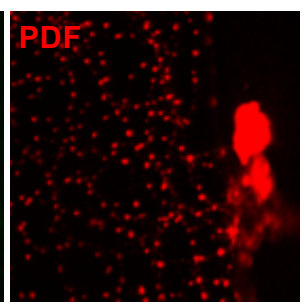
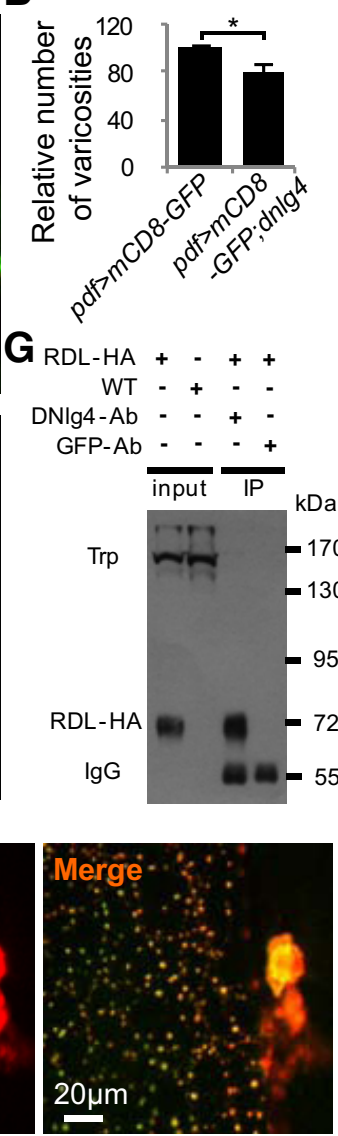

$\mathrm{DNIg} 4-\mathrm{Ab}-++\cdot$

GFP-Ab - - + +
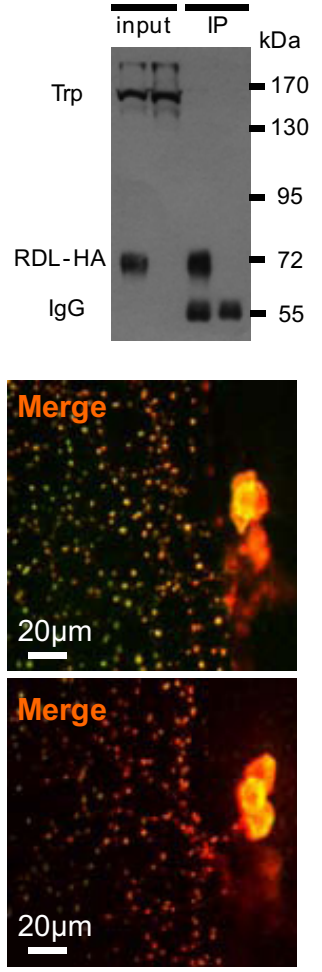

E

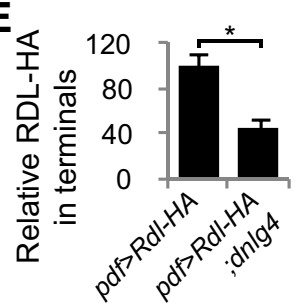

WT -+-
$\mathbf{F}$

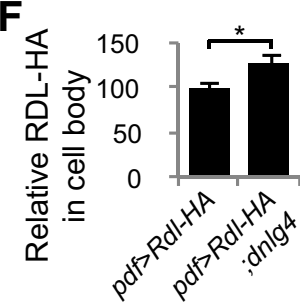

Figure 8. dnlg4 mutant flies exhibit reduced RDL clustering in I-LNvs, and DNIg4 associates with RDLs. A, Representative images showing the distribution of dendrite branches and number of varicosities in I-LNvs for wild-type (WT) and dnlg4 mutant flies. I-LNvs membranes were labeled with mCD8-GFP under the control of the $p d f$-Gal 4 driver. Dissected whole brains were stained with anti-GFP (green) and anti-PDF (red) antibodies. Scale bar, $50 \mu \mathrm{m}$. B, Quantification of the number of I-LNv varicosities. Eight images were used for quantification for WT and $d n l g 4$ mutant flies. Each image was taken from a different fly. $C$, Distribution of RDL-HA in I-LNvs neurons. RDL-HA was expressed in PDF neurons under the control of the pdf-Gal4 driver. Dissected whole brains were stained with anti-HA (green) and anti-PDF (red) antibodies. Scale bar, $20 \mu \mathrm{m}$. D, Quantification of the number of RDL-HApositive varicosities in I-LNv neurons. $\boldsymbol{E}$, Quantification of average RDL-HA protein amount in RDL-HA-positive varicosities in I-LNvs. $\boldsymbol{F}$, Quantification of RDL-HA protein amount in I-LNv somata. $C-F$, Siximages were used for quantification for WT and dnlg4 mutant flies. Each image was taken from a different fly. G, Co-immunoprecipitation of DNIg4 and Rdl in vivo. The precipitates and a portion (1\% of the input) of the head extracts were subjected to Western blotting with anti-HA or anti-TRP (negative control) antibodies.

mals, inhibitory GABAergic neurons, which are located in the ventrolateral preoptic area of the hypothalamus, are involved in sleep (Sehgal and Mignot, 2011). Thus, we suspect that Nlg2 may also regulate sleep in mammals. Furthermore, based on its role in 
regulating $\mathrm{GABA}_{\mathrm{A}}$ receptor clustering, DNlg4 may be functionally equivalent to $\mathrm{Nlg} 2$ in mammals.

\section{DNlg4 modulates RDL clustering}

Nlgs are postsynaptic cell adhesion molecules that are thought to function in synaptogenesis. Both $d n \lg 1$ and $d n \lg 2$ mutants exhibit a severe reduction in bouton number at neuromuscular junctions (Banovic et al., 2010; Sun et al., 2011; Chen et al., 2012). Using mCD8-GFP and anti-PDF labeling, we showed that the number of LNv varicosities was reduced in dnlg4 mutant flies compared with wild-type flies. RDL puncta in l-LNv varicosities has been shown to represent synaptic inputs to LNv dendrites (Chung et al., 2009). Here, we found that HA-tagged RDL puncta appeared in most l-LNv varicosities in wild-type flies but in only some varicosities in dnlg4 mutant flies. These results provide solid evidence that DNlg4 is essential for the number of GABAergic synapse in l-LNvs.

In addition to synaptogenesis, Nlgs also play essential roles in synapse maturation through regulating postsynaptic protein assembly. In mammals, Nlg1 determines the number of functional NMDARs at glutamatergic synapses (Wittenmayer et al., 2009). In the mouse retina, the absence of Nlg2 results in a severe reduction of $\mathrm{GABA}_{\mathrm{A}}$ receptor clustering (Hoon et al., 2009). In Drosophila, both DNlg1 and DNlg2 promote the accumulation of postsynaptic GluRs at neuromuscular terminals (Banovic et al., 2010; Sun et al., 2011; Chen et al., 2012). The present study shows that RDL clustering is impaired in dnlg4 mutant flies and that $\mathrm{DNlg} 4$ associates with RDL in vivo, suggesting that DNlg4 modulates RDL clustering through associating with RDLs.

\section{References}

Agosto J, Choi JC, Parisky KM, Stilwell G, Rosbash M, Griffith LC (2008) Modulation of GABAA receptor desensitization uncouples sleep onset and maintenance in Drosophila. Nat Neurosci 11:354-359. CrossRef Medline

Banovic D, Khorramshahi O, Owald D, Wichmann C, Riedt T, Fouquet W, Tian R, Sigrist SJ, Aberle H (2010) Drosophila neuroligin 1 promotes growth and postsynaptic differentiation at glutamatergic neuromuscular junctions. Neuron 66:724-738. CrossRef Medline

Budreck EC, Scheiffele P (2007) Neuroligin-3 is a neuronal adhesion protein at GABAergic and glutamatergic synapses. Eur J Neurosci 26:17381748. CrossRef Medline

Cao J, Li Y, Xia W, Reddig K, Hu W, Xie W, Li HS, Han J (2011) A Drosophila metallophosphoesterase mediates deglycosylation of rhodopsin. EMBO J 30:3701-3713. CrossRef Medline

Chemelli RM, Willie JT, Sinton CM, Elmquist JK, Scammell T, Lee C, Richardson JA, Williams SC, Xiong Y, Kisanuki Y, Fitch TE, Nakazato M, Hammer RE, Saper CB, Yanagisawa M (1999) Narcolepsy in orexin knockout mice: molecular genetics of sleep regulation. Cell 98:437-451. CrossRef Medline

Chen YC, Lin YQ, Banerjee S, Venken K, Li J, Ismat A, Chen K, Duraine L, Bellen HJ, Bhat MA (2012) Drosophila neuroligin 2 is required presynaptically and postsynaptically for proper synaptic differentiation and synaptic transmission. J Neurosci 32:16018-16030. CrossRef Medline

Chung BY, Kilman VL, Keath JR, Pitman JL, Allada R (2009) The GABA(A) receptor RDL acts in peptidergic PDF neurons to promote sleep in Drosophila. Curr Biol 19:386-390. CrossRef Medline

Cirelli C (2009) The genetic and molecular regulation of sleep: from fruit flies to humans. Nat Rev Neurosci 10:549-560. CrossRef Medline

Cirelli C, Bushey D, Hill S, Huber R, Kreber R, Ganetzky B, Tononi G (2005) Reduced sleep in Drosophila Shaker mutants. Nature 434:1087-1092. CrossRef Medline

Crocker A, Sehgal A (2010) Genetic analysis of sleep. Genes Dev 24:12201235. CrossRef Medline

Donlea JM, Thimgan MS, Suzuki Y, Gottschalk L, Shaw PJ (2011) Inducing sleep by remote control facilitates memory consolidation in Drosophila. Science 332:1571-1576. CrossRef Medline

El Helou J, Bélanger-Nelson E, Freyburger M, Dorsaz S, Curie T, La Spada F,
Gaudreault PO, Beaumont É, Pouliot P, Lesage F, Frank MG, Franken P, Mongrain V (2013) Neuroligin-1 links neuronal activity to sleep-wake regulation. Proc Natl Acad Sci U S A 110:9974-9979. CrossRef Medline

Fogle KJ, Parson KG, Dahm NA, Holmes TC (2011) CRYPTOCHROME is a blue-light sensor that regulates neuronal firing rate. Science 331: 1409-1413. CrossRef Medline

Ganguly-Fitzgerald I, Donlea J, Shaw PJ (2006) Waking experience affects sleep need in Drosophila. Science 313:1775-1781. CrossRef Medline

Hendricks JC, Finn SM, Panckeri KA, Chavkin J, Williams JA, Sehgal A, Pack AI (2000) Rest in Drosophila is a sleep-like state. Neuron 25:129-138. CrossRef Medline

Hoon M, Bauer G, Fritschy JM, Moser T, Falkenburger BH, Varoqueaux F (2009) Neuroligin 2 controls the maturation of GABAergic synapses and information processing in the retina. J Neurosci 29:8039-8050. CrossRef Medline

Hoon M, Soykan T, Falkenburger B, Hammer M, Patrizi A, Schmidt KF, Sassoè-Pognetto M, Löwel S, Moser T, Taschenberger H, Brose N, Varoqueaux F (2011) Neuroligin-4 is localized to glycinergic postsynapses and regulates inhibition in the retina. Proc Natl Acad Sci U S A 108:30533058. CrossRef Medline

Huber R, Hill SL, Holladay C, Biesiadecki M, Tononi G, Cirelli C (2004) Sleep homeostasis in Drosophila melanogaster. Sleep 27:628-639. Medline

Ichtchenko K, Nguyen T, Südhof TC (1996) Structures, alternative splicing, and neurexin binding of multiple neuroligins. J Biol Chem 271: 2676-2682. CrossRef Medline

Joiner WJ, Crocker A, White BH, Sehgal A (2006) Sleep in Drosophila is regulated by adult mushroom bodies. Nature 441:757-760. CrossRef Medline

Knight D, Xie W, Boulianne GL (2011) Neurexins and neuroligins: recent insights from invertebrates. Mol Neurobiol 44:426-440. CrossRef Medline

Kula-Eversole E, Nagoshi E, Shang Y, Rodriguez J, Allada R, Rosbash M (2010) Surprising gene expression patterns within and between PDFcontaining circadian neurons in Drosophila. Proc Natl Acad Sci U S A 107:13497-13502. CrossRef Medline

Lin L, Faraco J, Li R, Kadotani H, Rogers W, Lin X, Qiu X, de Jong PJ, Nishino S, Mignot E (1999) The sleep disorder canine narcolepsy is caused by a mutation in the hypocretin (orexin) receptor 2 gene. Cell 98:365-376. CrossRef Medline

Liu Q, Liu S, Kodama L, Driscoll MR, Wu MN (2012) Two dopaminergic neurons signal to the dorsal fan-shaped body to promote wakefulness in Drosophila. Curr Biol 22:2114-2123. CrossRef Medline

McGuire SE, Mao Z, Davis RL (2004) Spatiotemporal gene expression targeting with the TARGET and gene-switch systems in Drosophila. Sci STKE 2004:pl6. Medline

Mungenast AE, Ojeda SR (2005) Expression of three gene families encoding cell-cell communication molecules in the prepubertal nonhuman primate hypothalamus. J Neuroendocrinol 17:208-219. CrossRef Medline

Nitz DA, van Swinderen B, Tononi G, Greenspan RJ (2002) Electrophysiological correlates of rest and activity in Drosophila melanogaster. Curr Biol 12:1934-1940. CrossRef Medline

Pace-Schott EF, Hobson JA (2002) The neurobiology of sleep: genetics, cellular physiology and subcortical networks. Nat Rev Neurosci 3:591-605. Medline

Parisky KM, Agosto J, Pulver SR, Shang Y, Kuklin E, Hodge JJ, Kang K, Liu X, Garrity PA, Rosbash M, Griffith LC (2008) PDF cells are a GABAresponsive wake-promoting component of the Drosophila sleep circuit. Neuron 60:672-682. CrossRef Medline

Pitman JL, McGill JJ, Keegan KP, Allada R (2006) A dynamic role for the mushroom bodies in promoting sleep in Drosophila. Nature 441:753756. CrossRef Medline

Renn SC, Park JH, Rosbash M, Hall JC, Taghert PH (1999) A pdf neuropeptide gene mutation and ablation of PDF neurons each cause severe abnormalities of behavioral circadian rhythms in Drosophila. Cell 99:791-802. CrossRef Medline

Scheiffele P, Fan J, Choih J, Fetter R, Serafini T (2000) Neuroligin expressed in nonneuronal cells triggers presynaptic development in contacting axons. Cell 101:657-669. CrossRef Medline

Sehgal A, Mignot E (2011) Genetics of sleep and sleep disorders. Cell 146: 194-207. CrossRef Medline

Shang Y, Griffith LC, Rosbash M (2008) Light-arousal and circadian photo- 
reception circuits intersect at the large PDF cells of the Drosophila brain. Proc Natl Acad Sci U S A 105:19587-19594. CrossRef Medline

Shaw PJ, Cirelli C, Greenspan RJ, Tononi G (2000) Correlates of sleep and waking in Drosophila melanogaster. Science 287:1834-1837. CrossRef Medline

Sheeba V, Gu H, Sharma VK, O’Dowd DK, Holmes TC (2008a) Circadian- and light-dependent regulation of resting membrane potential and spontaneous action potential firing of Drosophila circadian pacemaker neurons. J Neurophysiol 99:976-988. CrossRef Medline

Sheeba V, Fogle KJ, Kaneko M, Rashid S, Chou YT, Sharma VK, Holmes TC (2008b) Large ventral lateral neurons modulate arousal and sleep in Drosophila. Curr Biol 18:1537-1545. CrossRef Medline

Song JY, Ichtchenko K, Südhof TC, Brose N (1999) Neuroligin 1 is a postsynaptic cell-adhesion molecule of excitatory synapses. Proc Natl Acad Sci U S A 96:1100-1105. CrossRef Medline

Sun M, Xing G, Yuan L, Gan G, Knight D, With SI, He C, Han J, Zeng X, Fang M, Boulianne GL, Xie W (2011) Neuroligin 2 is required for synapse development and function at the Drosophila neuromuscular junction. J Neurosci 31:687-699. CrossRef Medline

Szatmari P, Paterson AD, Zwaigenbaum L, Roberts W, Brian J, Liu XQ, Vincent JB, Skaug JL, Thompson AP, Senman L, Feuk L, Qian C, Bryson SE, Jones MB, Marshall CR, Scherer SW, Vieland VJ, Bartlett C, Mangin LV, Goedken R, et al. (2007) Mapping autism risk loci using genetic linkage and chromosomal rearrangements. Nat Genet 39:319-328. CrossRef Medline

Taghert PH, Hewes RS, Park JH, O’Brien MA, Han M, Peck ME (2001)
Multiple amidated neuropeptides are required for normal circadian locomotor rhythms in Drosophila. J Neurosci 21:6673-6686. Medline

Tian Y, Li T, Sun M, Wan D, Li Q, Li P, Zhang ZC, Han J, Xie W (2013) Neurexin regulates visual function via mediating retinoid transport to promote rhodopsin maturation. Neuron 77:311-322. CrossRef Medline

Ueno T, Tomita J, Tanimoto H, Endo K, Ito K, Kume S, Kume K (2012) Identification of a dopamine pathway that regulates sleep and arousal in Drosophila. Nat Neurosci 15:1516-1523. CrossRef Medline

van Swinderen B, Nitz DA, Greenspan RJ (2004) Uncoupling of brain activity from movement defines arousal states in Drosophila. Curr Biol 14:8187. CrossRef Medline

Varoqueaux F, Jamain S, Brose N (2004) Neuroligin 2 is exclusively localized to inhibitory synapses. Eur J Cell Biol 83:449-456. CrossRef Medline

Varoqueaux F, Aramuni G, Rawson RL, Mohrmann R, Missler M, Gottmann K, Zhang W, Südhof TC, Brose N (2006) Neuroligins determine synapse maturation and function. Neuron 51:741-754. CrossRef Medline

Wittenmayer N, Körber C, Liu H, Kremer T, Varoqueaux F, Chapman ER, Brose N, Kuner T, Dresbach T (2009) Postsynaptic Neuroligin1 regulates presynaptic maturation. Proc Natl Acad Sci U S A 106:13564-13569. CrossRef Medline

Young JM, Armstrong JD (2010) Structure of the adult central complex in Drosophila: organization of distinct neuronal subsets. J Comp Neurol 518:1500-1524. CrossRef Medline

Zhang HG, ffrench-Constant RH, Jackson MB (1994) A unique amino acid of the Drosophila GABA receptor with influence on drug sensitivity by two mechanisms. J Physiol 479:65-75. Medline 